\title{
Neurally Adjusted Vetilatory Assist in the Newborn
}

Fermin Garci-Munoz Rodrigo* and Sonia Rivero Rodríguez

Complejo Hospitalario Universitario Insular Materno-Infantil de Las Palmas de Gran Canaria, Spain

*Corresponding author: Fermin García-MuñozRodrigo, Complejo Hospitalario Universitario Insular Materno-Infantil de Las Palmas de Gran Canaria, Spain, Tel: +34 680406241; E-mail: fgarciamu@gmail.com

Rec date: March 20, 2014; Acc date: April 14, 2014; Pub date: April 16, 2014

Copyright: (c) 2014 Garcia-Muñoz Rodrigo F, et al. This is an open-access article distributed under the terms of the Creative Commons Attribution License, which permits unrestricted use, distribution, and reproduction in any medium, provided the original author and source are credited.

\begin{abstract}
Invasive and noninvasive ventilation of the newborn may be associated with local and systemic complications due to mechanical trauma to lung tissues and their inflammatory response. A key objective, therefore, of any type of mechanical ventilation is to reduce its duration and the side effects related to it. Neurally Adjusted Ventilatory Assist (NAVA), a method that uses the Electrical Activity of the diaphragm (EAdi) as a signal to trigger the mechanical ventilatory breaths, may improve synchronization between patient and ventilator and optimize the volume of gas delivered to the lungs, according to the patient needs, eventually reducing volu- and biotrauma. The EAdi signal may also be used as vital sing to monitor the patient's neural respiratory drive. Preliminary data show some benefit with the use of NAVA in the neonatal period, but further studies are needed to assess whether these short-term benefits are reflected in better outcomes in the long run.
\end{abstract}

Keywords: Electrical activity of the diaphragm; Neural trigger; Neurally adjusted ventilatory assist; Non-Invasive ventilation; Synchrony; Asyncrony; Patient-ventilator interaction

\section{Abbreviations}

EAdi: Electrical Activity of the diaphragm; NAVA: Neurally Adjusted Ventilatory Assist; NIV: Non-Invasive ventilation; $\mathrm{V}_{\mathrm{T}}$ : Tidal Volume; $\mu \mathrm{V}$ : micro-volt

\section{Introduction}

Respiratory support with mechanical ventilation of preterm infants with Respiratory Distress Syndrome (RDS) has been a fundamental tool in the progressive increase in the survival of patients since its introduction and generalization in the late 60's [1]. However, it soon became clear that their use could also lead to significant lung damage [2]. Other interventions were incorporated subsequently contributing significantly to improve the prognosis of these children: antenatal steroids [3], exogenous surfactant [4], caffeine [5], etc. The use of Non-Invasive Ventilation (NIV) is currently recommended, whenever possible, and in cases where intubation is required, the total time of mechanical ventilation should be as short as possible [6]. Furthermore, synchronized and volume guarantee modalities are preferable because they have proved to shorten the duration of invasive ventilation and reduce the episodes of hyperventilation [7,8]. Neurally Adjusted Ventilatory Assist (NAVA) is a relatively new modality of mechanical ventilation in which the ventilator is cycled by changes in the Electrical Activity of the diaphragm (EAdi), in both invasive and non-invasive modalities. Potentially, this mode of mechanical ventilation could achieve a better interaction between patient and machine and a higher level of comfort. At present there is little experience in the use of this ventilatory modality in the neonate.

\section{Catheter Positioning and EAdi Measurement}

A nasogastric feeding tube, embedded with electrodes, is inserted through the nose or mouth, and the electrodes are placed at the level of the crural diaphragm. It is important to select the appropriate EAdi catheter according to the patient weight or height. After accurately measuring the nose-ear-xiphoid distance, the catheter length to be introduced can be calculated with the aid of a formula provided by the manufacturer. Further adjustments should be accomplished with the aid of the catheter-positioning screen (Figure 1), a tool provided by the Servo-i or Servo-n ventilators (Maquet, Solna, Sweden). In this screen the system displays four retrocardiac electrocardiographic leads. When the catheter is appropriately situated, the uppermost lead displays the largest p-waves and QRS complexes, and these gradually decrease in size until they near disappear in the lower lead. In the inferior part of the screen the EAdi signal is displayed. When the catheter is correctly placed, the middle two traces change to blue or purple in the Servo-i or Servo-n, respectively, coinciding with the EAdi signal. The new Servo$\mathrm{n}$ also displays in this screen a representation of the EAdi catheter with its nine electrodes, the five most central of which are also highlighted in purple when the catheter is correctly placed. If the third and fourth traces are highlighted, the catheter should be introduced a little bit more. On the contrary, if the first and second traces are highlighted, the catheter should be removed until after the second and third traces are displayed in blue/purple during the EAdi signal (Figure 1). Although small changes in the catheter position without loss of the signal integrity are tolerable, a common concern among clinicians when using this ventilatory mode is the possible displacement of the catheter with the consequent loss of the EAdi signal. It is important to check frequently its location, and to reposition it whenever necessary. Oral or catheter feedings do not interfere with signal acquisition or with its transmission, but there are some reasons for failure to detect the EAdi. The most common are central apnea, brain damage, sedation, hyperventilation, congenital diaphragmatic hernia, and phrenic nerve injury [9]. 


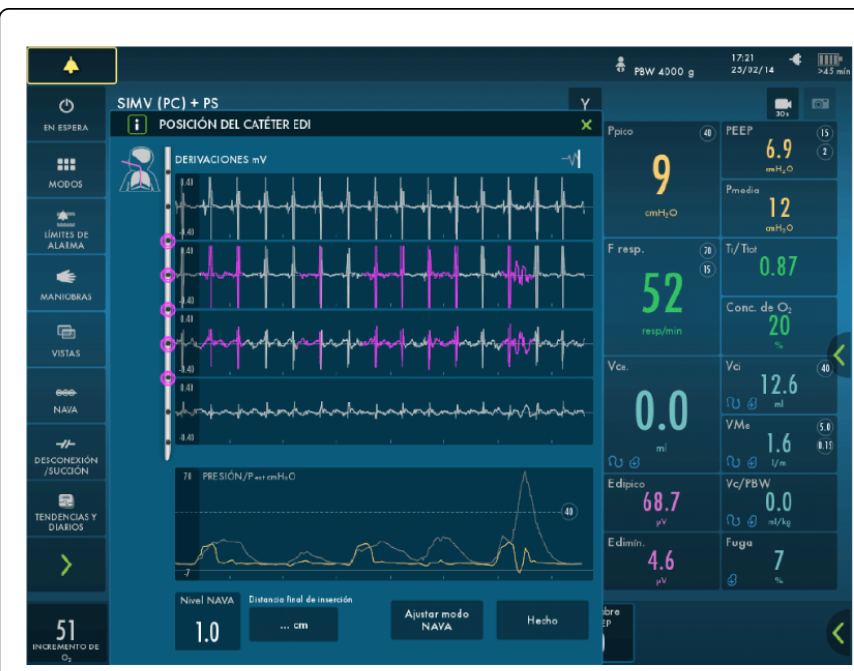

Figure 1: Nasogastric catheter appropriately placed. The uppermost lead displays the largest p-waves and QRS complexes, and these gradually decrease in size until they near disappear in the lower lead. The middle two traces are highlighted in purple during the EAdi signal, showed in the inferior part of the screen. The new Servo-n also displays in this screen, to the left of the leads, a representation of the EAdi catheter with its nine electrodes, the five most central of which are also highlighted in purple when the catheter is correctly placed.

\section{Practical Considerations and Experience in the Neonatal Period}

The EAdi module allows the detection of the onset, intensity, duration and frequency of the diaphragmatic electrical activity (neural inspiratory effort), transmitting the signal to the ventilator where it is transformed into pressure proportional to its intensity and duration. Therefore, the patient determines the initiation of the insufflation, the tidal volume and the respiratory rate. He can also take deeper breaths (sighs) periodically, which may amount to lung recruitment maneuvers, with the intensity and frequency that the patient's own nervous system regulates. The minimum EAdi reflects the tonic activity of the diaphragm at rest [10]. The EAdi waveform is a useful tool for patient-ventilator monitoring [11], and correlates with the trans-diaphragmatic pressure and with the patient's respiratory efforts. The clinician, through adjustments in the NAVA level, determines the proportion in which the machine "download" the patient's respiratory muscles, and gradually reduces this help as the patient clinical condition improves.

Severe asynchrony during ventilation has been described frequently in the adult and pediatric populations, and it results in the need to increase the Mean Airway Pressure (MAP) or the inspired fraction of oxygen $\left(\mathrm{FiO}_{2}\right)$, and/or in the need of sedation or muscle relaxation. Eventually, this could result in an increased time of mechanical ventilation, shorter ventilation free survival, longer length of stay, and lower likelihood of patients' home discharge [12]. Although less commonly reported, asynchronies are also frequent in the neonatal period and they may have direct adverse effect in the lung, and also in other organs due to the fluctuations in the blood and intracranial pressure, or to the production of inflammatory mediators.
Most current neonatal ventilators use flow changes measured by a sensor in the proximal patient's airway (Y-piece) to trigger mechanical ventilation with a pre-set tidal volume, inspiratory pressure, and/or inspiratory time. The lungs insufflations may or may not be synchronized with the patient's efforts, and they can be generated even without these (auto-cycling), out of phase (neural inspiratory time different than the mechanical inspiratory time), or totally lost (the machine do not respond to the patient's efforts) $[13,14]$. In addition, most commonly used devices for NIV usually do not have the capability to synchronize the machine with the patient's respirations. In general, the currently used technology imposes some kind of restriction on the patient's respiratory system (trigger variable, form of gas delivery, cycling termination criteria, etc.). As a result, the time spent on the ventilator is prolonged, and the risks of ventilator induced lung injury (VILI) [15] and ventilator-induced diaphragmatic dysfunction (VIDD) in form of muscle atrophy, oxidative stress and ultrastructural damage, increases $[16,17]$. In the newborn infant, the risks of developing bronchopulmonary dysplasia, and other local and systemic complications have been described, including derangements in the neurodevelopment [18]. Therefore, weaning and extubation should be undertaken as soon as possible. However, the establishment of reliable and safe criteria to avoid the risk of extubation failure is far from being achieved [19].

In the newborn infant it is especially difficult to achieve good patient-ventilator synchronization due to its breathing characteristics: rapid respiratory rates, small tidal volumes, periodic breathing, short inspiratory times, etc. [20]. Under these circumstances, NAVA is a promising technology because, in addition to triggering the onset of breathing, the patient controls the tidal volume, the inspiratory "plateau", and the end of the respiratory cycle, with a faster response time from the machine and a better level of synchronization than the traditional flow or pressure systems, achieving a higher level of comfort in the patient [21]. Actually, some studies have demonstrated an improved patient-ventilator interaction with NAVA in the neonatal period [22], even in the presence of large air leaks [23]. Most studies have found no significant adverse events with the use of NAVA in the neonatal period [24]. The loss of the signal and the presence of periodic breathing or apnea in the neonate may limit the effectiveness of this method. However, the ventilator automatically changes to pressure support (PS) if the patient is breathing but the EAdi signal is not recognized, or to pressure control (PC) with pre-selected parameters, in cases of apnea. On the other hand, the current ability to monitor the Edi activity and to assess the neuro-ventilatory efficiency during a trial of spontaneous breathing on CPAP, i.e., the tidal volume generated by each $\mu \mathrm{V}$ of EAdi ( $\left.\mathrm{V}_{\mathrm{T}} / \mathrm{EAdi}\right)$, could be a useful tool to consider weaning initiation and to decide when a patient is ready for extubation [25].

Recently, we reported a preliminary experience with two preterm babies with severe RDS that could be successfully weaned and extubated with the help of this ventilatory modality [26], and we have used NAVA frequently thereafter in preterm and full-term infants with good results (Figures 2 and 3). Our most frequent observation, in accordance we previous work, was a reduction in the Peak Inspiratory Pressure (PIP) and in the need of $\mathrm{FiO} 2$, after changing from S-IMV, A/C or Pressure Regulated Volume Control (PRVC) to NAVA. We also observed a reduction in respiratory rate and an increase in the patients' comfort. After extubation, during NIV-NAVA, the patients remained stable and confortable, even with the presence of air-leaks up to $90 \%$. There was no need of re-intubation in any case, although they had needed several re-intubations previously when assisted with non- 
synchronized devices. The lack of synchrony between diaphragmatic contraction and the opening of the upper airway may be the cause of obstructive apneas and desaturations during non-synchronized NIV. The active glottal closure in response to a progressive increase in nasal Intermittent Positive Pressure Ventilation (nIPPV) has been demonstrated in an animal model [27], and it originates from bronchopulmonary receptors rather than from upper airway receptors [28]. A better neurally mediated co-ordination between the diaphragmatic stimulation and contraction and the upper airway reflexes of closure and relaxation [9] could be the reason for the greater comfort, less air swallowing and less apnea spells in patients assisted with NIV-NAVA. A comprehensive review and summary of results of the use of NAVA in the neonatal period has been recently reported by Stein et al. [29].

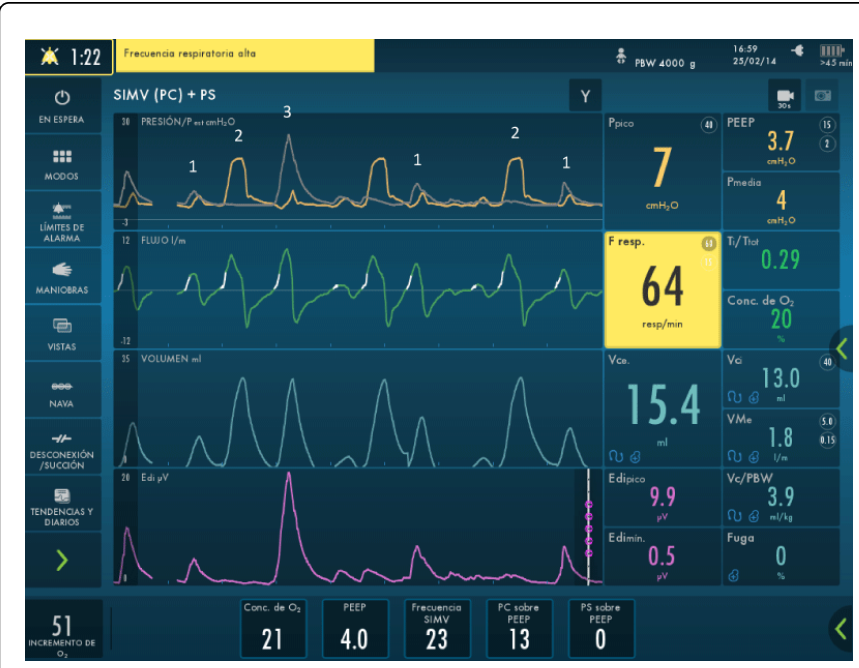

Figure 2: Types of asynchronies in a 4,000 g female newborn, ventilated because of meconium aspiration syndrome (MAS) with S-IMV (pressure-controlled) plus pressure support (PS). The first row shows the delivered inspiratory pressure, in yellow, superimposed to the pressure estimate, in gray, representing the estimated pressure if the patient was ventilating in neurally adjusted ventilatory assist (NAVA). This pressure estimated is calculated by the ventilator taking into account the EAdi signal and the selected NAVA level. The second line shows the flow; the third the delivered volume, and the fourth the electrical activity of the diaphragm (EAdi). 1) Trigger delay. 2) Auto-triggering: flow-triggered pressure support without respiratory drive. 3) Trigger delay, pressure under-support, and early termination asynchrony. The total respiratory rate at this moment was $64 \mathrm{bpm}$; and the spontaneous $\mathrm{V}_{\mathrm{T}}$ and MAP varied widely.

\section{Conclusion}

In conclusion, during invasive and non-invasive NAVA the nervous system regulates the patient's breathing pattern according to his own needs, based on physiological reflexes. This allows a better lung recruitment and avoids dynamic over-inflation and potential biotrauma. The better patient-ventilator interaction results in greater patient comfort, with reduction of diaphragmatic fatigability and a shortening of the total time of invasive mechanical ventilation. In NIV-NAVA, the better synchronization and patient comfort could significantly diminish the rate of extubation failure. However, experience is limited in the neonatal period and further studies are needed to assess whether these initial benefits translate into a real reduction in morbidity and mortality in this patient group.

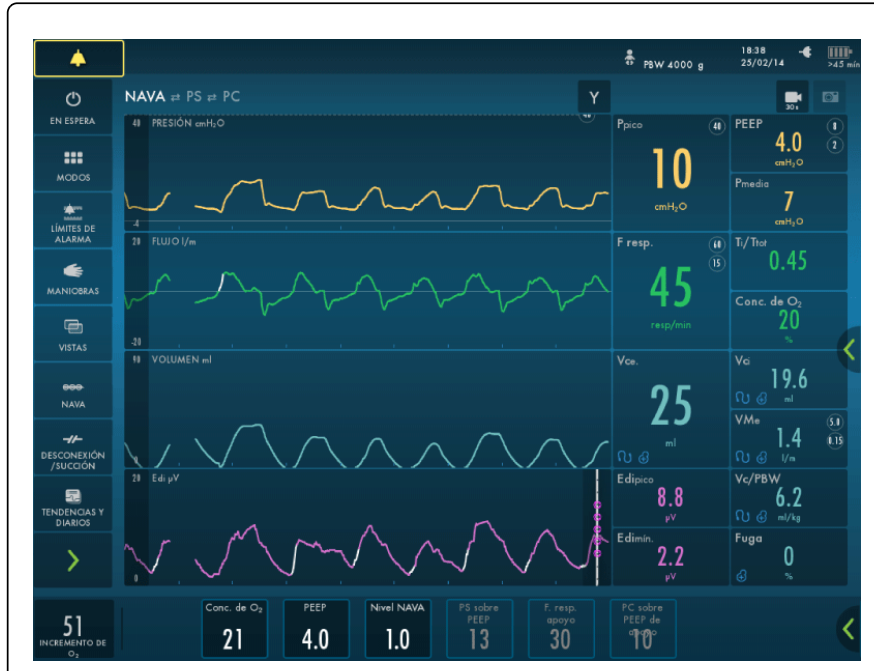

Figure 3: The same patient as in Figure 2, after changing to NAVA. A better patient-ventilator interaction was achieved with perfect synchronization between initiation, intensity of breathing, and cycling-off. The spontaneous $\mathrm{V}_{\mathrm{T}}$ in this moment was around 5-6ml per kilogram; the respiratory rate $45 \mathrm{bpm}$, and the MAP $7 \mathrm{~cm} \mathrm{H} \mathrm{H}_{2} \mathrm{O}$.

\section{References}

1. Reynolds EOR, Taghizadeh A (1974) Improved prognosis of infants mechanically ventilated for hyaline membrane disease. Arch Dis Child 49: 505-515.

2. Northway WH, Rosan RC, Porter DY (1967) Pulmonary Disease Following Respirator Therapy of Hyaline-Membrane Disease: Bronchopulmonary Dysplasia. N Engl J Med 276: 357-368.

3. Roberts D, Dalziel S (2006) Antenatal corticosteroids for accelerating fetal lung maturation for women at risk of preterm birth. Cochrane Database Syst Rev 3: CD004454.

4. Soll RF, Morley CJ (2001) Prophylactic versus selective use of surfactant in preventing morbidity and mortality in preterm infants. Cochrane Database Syst Rev CD000510.

5. Schmidt B, Roberts RS, Davis P, Doyle LW, Barrington KJ, et al. (2007) Caffeine for Apnea of Prematurity Trial Group. Long-term effects of caffeine therapy for apnea of prematurity. N Engl J Med 357: 1893-1902.

6. Sweet DG, Carnielli V, Greisen G, Hallman M, Ozek E, et al. (2013) European consensus guidelines on the management of neonatal respiratory distress syndrome in preterm infants - 2013 update. Neonatology 103: 353-368.

7. Greenough A, Dimitriou G, Prendergast M, Milner AD (2008) Synchronized mechanical ventilation for respiratory support in newborn infants. Cochrane Database Syst Rev CD000456.

8. Wheeler K, Klingenberg C, McCallion N, Morley CJ, Davis PG (2010) Volume targeted versus pressure-limited ventilation in the neonate. Cochrane Database Syst Rev CD003666.

9. Sinderby C, Beck J. Neurally adjusted ventilatory assist. Principles and practice of mechanical ventilation (3rd edn.) McGraw-Hill. Chicago, USA.

10. Sinderby C, Navalesi P, Beck J, Skrobik Y, Comtois N, et al. (1995) Neural control of mechanical ventilation in respiratory failure. Nat Med 5: 1433-1436. 
Citation: García-Muñoz Rodrigo F, Rivero Rodríguez S (2014) Neurally Adjusted Vetilatory Assist in the Newborn. J Neonatal Biol 3: 133. doi:

Page 4 of 4

11. Spahija J, de Marchie M, Albert M, Bellemare P, Delisle S, et al. (2010) Patient-ventilator interaction during pressure support ventilation and neurally adjusted ventilatory assist. Crit Care Med 38: 518-526.

12. de Wit M, Miller KB, Green DA, Ostman HE, Gennings C, et al. (2009) Ineffective triggering predicts increased duration of mechanical ventilation. Crit Care Med 37: 2740-2745.

13. Kondili E, Xirouchaki N, Georgopoulos D (2007) Modulation and treatment of patient ventilator dyssynchrony. Curr Opin Crit Care 13: 84-89.

14. Mellott KG, Grap MJ, Munro CL, Sessler CN, Wetzel PA (2009) Patientventilator dyssynchrony: clinical significance and implications for practice. Critical Care Nurse 29: 41-55.

15. Slusky AS, Ranieri VM (2013) Ventilator induced lung injury. N Engl Med 369: 2126-2136.

16. Vassilakopoulos T, Petrof BJ (2004) Ventilator-induced diaphragmatic dysfunction. Am J Resp Crit Care Med 169: 336-341.

17. Jaber S, Petrof BJ, Jung B, Chanques G, Berthet JP, et al. (2011) Rapidly Progressive Diaphragmatic Weakness and Injury during Mechanical Ventilation in Humans. Am J Respir Crit Care Med 183: 364-371.

18. Walsh MC, Morris BH, Wrage LA, Vohr BR, Poole WK, et al. (2005) Extremely low birthweight neonates with protracted ventilation: mortality and 18-month neurodevelopmental outcomes. J Pediatr 146 798-804.

19. Sant'Anna GM, Keszler M (2012) Weaning Infants from Mechanical Ventilation. Clin Perinatol 39: 543-562.

20. Keszler M (2009) State of the art in conventional mechanical ventilation. J Perinatol 29: 262e75.

21. de la Oliva P, Schüffelmann C, Gómez-Zamora A, Villar J, Kacmarek RM (2012) Asynchrony, neural drive, ventilatory variability and COMFORT:
NAVA versus pressure support in pediatric patients. A non-randomized cross-over trial. Intensive Care Med 38:838-846.

22. Alander M, Peltoniemi O, Pokka T, Kontiokari T (2012) Comparison of pressure-, flow-, and NAVA-triggering in pediatric and neonatal ventilatory care. Pediatr Pulmonol 47: 76-83.

23. Beck J, Reilly M, Grasselli G, Mirabella L, Slutsky AS, et al. (2009) Pediatr Res 65: 663-668.

24. Stein HM, Howard D (2012) Neurally adjusted ventilatory assist (NAVA) in neonates less than 1500 grams: a retrospective analysis. J Pediatr 160: 786-789.

25. Liu L, Liu H, Yang Y, Huang Y, Liu S, et al. (2012) Neuroventilatory efficiency and extubation readiness in critically ill patients. Critical Care 16: R143.

26. García-Muñoz Rodrigo F, Rivero Rodríguez S, Florido Rodríguez A, Martín Cruz FG, Díaz Pulido R (2014) Successful weaning and extubation in the premature newborn using neurally adjusted ventilatory assist. An Pediatr (Barc): in press.

27. Moreau-Bussière F, Samson N, St-Hilaire M, Reix P, Lafond JR, et al. (2007) Laryngeal response to nasal ventilation in nonsedated newborn lambs. J Appl Physiol 102: 2149-2157.

28. Roy B, Samson N, Moreau-Bussière F, Ouimet A, Dorion D, et al. (2008) Mechanisms of active laryngeal closure during noninvasive intermittent positive pressure ventilation in nonsedated lambs. J Appl Physioln 105: 1406-1412.

29. Stein H, Firestone K (2014) Application of neurally adjusted ventilatory assist in neonates. Semin Fetal Neonatal Med 19: 60-69. 